\title{
ILUSTRACJE Z DZIEWIECTNASTOWIECZNEJ PRASY KRÓLESTWA POLSKIEGO JAKO ŹRÓDŁO DO BADAŃ NAD KULTURĄ UZDROWISKOWĄ
}

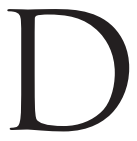

ruga połowa XIX wieku przyniosła w Królestwie Polskim wyraźny postęp w rozwoju techniki drukarskiej. Postępował wówczas szybki proces przekształcania rzemiosła drukarskiego w przemysł poligraficzny, a zmiany te związane były z przewrotem technicznym w tej dziedzinie. Jednocześnie rosło zapotrzebowanie społeczne na produkcję poligraficzną, gdyż zwiększał się poważnie krąg odbiorców wraz z rosnącą liczbą inteligencji i zmniejszaniem się liczby analfabetów. Czynniki te pociągały za sobą rozpowszechnianie się skomercjalizowanych i wyspecjalizowanych wydawnictw periodycznych, a liczba tytułów regularnie wzrastała ${ }^{1}$. Poważne zmiany zachodziły również w kwestii rozwoju grafiki ilustracyjnej. Technika litograficzna, dominująca przez kilka pierwszych dekad XIX stulecia, uzupełniona została przez rozwijające się na szeroką skalę drzeworytnictwo, a pod koniec wieku zaczęto wprowadzać autotypię². Dzięki temu podniósł się wyraźnie poziom edytorski czasopism ilustrowanych, które należały do najchętniej prenumerowanych czasopism we wszystkich częściach dawnej Rzeczypospolitej.

Drzeworyt jako technika sprawozdawcza przeznaczona do ilustracji prasowej uprawiany był w XIX w. przez najwybitniejszych ówczesnych polskich artystów. Józef Kenig z okazji trzydziestolecia „Tygodnika Ilustrowanego” napisał:

Jakże wiele można by o tem powiedzieć co „Tygodnik” winien malarzom naszym, zaczynając od Matejki, Kossaka, Gersona, Kostrzewskiego, co winien tym artystom, tak starszego,

${ }^{1}$ Zob. szerzej: S. Lewandowski, Poligrafia warszawska 1870-1914, Warszawa 1982; Z. Kmiecik, Prasa warszawska w okresie pozytywizmu (1864-1885), Warszawa 1971; tenże, Prasa warszawska w latach 1886-1904, Wrocław 1989; tenże, Prasa warszawska w latach 1908-1918, Warszawa 1981.

${ }^{2}$ M. Opałek, Drzeworyt w czasopismach polskich XIX stulecia, Wrocław 1949; A. Banach, Polska książka ilustrowana 1800-1900, Kraków 1959; A. Socha, Andriolli i rozwój drzeworytu w Polsce, Wrocław 1988; L. Cichocki, T. Pawlicki, I. Ruczka, Poligraficzny stownik terminologiczny, Warszawa 1999. 
jak młodszego pokolenia, bo przez lat trzydzieści wszyscy go wspierali, i nie ma między nimi poważniejszego nazwiska, z którym by się nie spotkało w tym archiwum sztuki naszej³

Właśnie za sprawą „Tygodnika Ilustrowanego”, najbardziej poczytnego wówczas pisma ilustrowanego na ziemiach polskich, w drugiej połowie XIX wieku nastąpił rozkwit polskiego drzeworytu reprodukcyjnego. Założona przy redakcji czasopisma pracownia drzeworytnicza dostarczała znakomitej jakości, jak na ówczesne warunki, prace ilustracyjne. W latach 1862-1868 działem ilustracyjnym pisma kierował Juliusz Kossak, znakomity malarz. Wśród ilustratorów przez lata pojawiały się nazwiska takich wybitnych twórców jak: Wojciech Gerson, Franciszek Kostrzewski, Michał Elwiro Andriolli czy Ksawery Pillati, a pośród drzeworytników działali tak znakomici przedstawiciele ksylografii jak: Józef Holewiński ${ }^{4}$, Jan Styfi ${ }^{5}$, Edward Gorazdowski, Aleksander Regulski, Franciszek Tegazzo.

Przeprowadzając analizę nazwisk artystów zamieszczających swoje prace w ówczesnych czasopismach ilustrowanych Królestwa Polskiego rzeczywiście można wysnuć wniosek, iż przez warszawską prasę ilustrowaną drugiej połowy XIX wieku przewinęła się plejada najznakomitszych polskich artystów. Trudno wskazać, aby którykolwiek z naszych ówczesnych malarzy i rysowników, choćby przez krótki okres, nie współpracował z „Tygodnikiem Ilustrowanym”, „Kłosami” czy „Wędrowcem”. Ilustratorstwo czasopism i książek rozwijało się bowiem w bezpośrednim związku z rozwojem drzeworytnictwa, jako podstawowej w tym okresie techniki reprodukowania grafiki i malarstwa. Praca ilustratorska była dla niektórych artystów głównym zajęciem, a nawet pasją, z kolei dla innych pracą dorywczą, podejmowaną głównie z pobudek finansowych. Wskazują chociażby na to słowa Aleksandra Gierymskiego, który w jednym z listów pisał:

(...) jestem biedny, muszę zarabiać drzeworytami, staram się zebrać paręset guldenów, żebym mógł z pierwszym marca pojechać do Włoch i prawie tylko malować. To jest lepsze aniżeli jedno z drugim pół na pół, bo nie wychodzi na zupełną szkodę malarstwa ${ }^{6}$.

Należy jednak podkreślić, iż współpraca z redakcjami pism ilustrowanych stanowiła dla artystów nie tylko ważne źródło utrzymania, okresami nawet jedyne, ale jednocześnie umożliwiała im prezentowanie swoich prac szerokiej publiczności, dawała przy tym popularność.

\footnotetext{
${ }^{3}$ J. Kenig, Drzeworytnictwo, ,Tygodnik Ilustrowany” 1889, t. X, nr 354, s. 231.

${ }^{4}$ Od 1891 r. dyrektor artystyczny „Tygodnika Ilustrowanego”. Wcześniej współpracował z czasopismami ilustrowanymi „Kłosy” i „Wędrowiec”.

${ }^{5}$ Kierownik drzeworytni przy „Tygodniku Ilustrowanym” i przy czasopiśmie „Kłosy”(1865-1890).

${ }^{6}$ List Aleksandra Gierymskiego do Prospera Dziekońskiego, Wiedeń, 1885, [w:] Maksymilian i Aleksander Gierymscy. Listy i notatki, oprac. J. Starzyński, H. Stępień, Wrocław-Warszawa-Kraków 1973, s. 245-246.
} 
Dzięki współpracy ze znakomitymi artystami czasopisma ilustrowane w Królestwie Polskim szybko rozwijały się i należały do najbardziej poczytnych periodyków w drugiej połowie XIX $w^{7}$. Na łamach tych czasopism pojawiały się jednak nie tylko dzieła malarskie naszych i obcych artystów, ale także cały szereg różnych motywów ikonograficznych, m.in.: widoki wszelkich budowli i urządzeń, panoramy i pejzaże polecanych do odwiedzenia miejsc i miejscowości, charakterystyczne typy polskiego i obcego ubioru, portrety wybitnych i zasłużonych dla polskiej kultury i historii osób, zarówno mężczyzn, jak i kobiet, sceny rodzajowe i batalistyczne, utwory humorystyczne.

W tym samym okresie co rozwój drzeworytnictwa i prasy ilustrowanej nastąpiła rewitalizacja kultury uzdrowiskowej w kontekście medycznym. Niejako na nowo „odkrywano" walory znanych od dawna europejskich kurortów, a coraz większą popularność zyskiwały swojskie uzdrowiska i zdrojowiska, które powstawały we wszystkich częściach ziem polskich, ale najwięcej na terenie Galicji, gdzie istniały liczne źródła wód mineralnych, a ponadto lecznicze warunki klimatyczne. Do znanych kurortów i mało znanych zdrojowisk i stacji klimatycznych wyjeżdżano nie tylko w celach leczniczych, ale peregrynacje uzdrowiskowe stały się wówczas modne i ważne pod względem kontaktów towarzyskich. Uzdrowiska XIX-wieczne to już nie tylko rozbudowane zakłady lecznicze, skupione na wykonywaniu coraz bardziej wyrafinowanych zabiegów celem poratowania kondycji zdrowotnej chorych i niedomagających ${ }^{8}$, ale w znacznym stopniu popularne miejsca wypoczynku i rekreacji dla ludzi zdrowych i młodych obojga płci. Wszechstronna działalność medyczna była w tym wypadku tylko pretekstem do przebywania $\mathrm{w}$ danym zdrojowisku. Wraz z nadejściem sezonu, trwającego najczęściej od kwietnia do października, do uzdrowisk, zdrojowisk, stacji klimatycznych i różnego typu podmiejskich wilegiatur wyruszali więc nie tylko chorzy i cierpiący, szukający tutaj pomocy i uzdrowienia, ale również panny poszukujące odpowiednich kandydatów do zamążpójścia, kawalerowie rozglądający się za posażnymi i odpowiednio ustawionymi towarzysko pannami, a dalej dystyngowane damy oczekujące na najnowsze plotki rozsiewane podczas spacerów na kuracyjnych deptakach oraz cała rzesza innych postaci,

które - jak pisał warszawski publicysta - przyjeżdżają tu bez celu, dla zabicia nudów, pokazania nowych toalet, a wszystko małym kosztem czasu i pieniędzy9.

${ }^{7}$ W 1875 r. nakład „Kłosów” wynosił 5400 egz., a „Tygodnika Ilustrowanego” 5000 egz. Czasopisma te przekraczały granice poszczególnych zaborów i docierały do czytelników w Galicji, w Wielkopolsce i na Kresach Wschodnich.

${ }^{8}$ Według Encyklopedii Powszechnej S. Orgelbranda, t. XV, Warszawa 1903, s. 241 - uzdrowiska to miejsca zasobne w źródła uzdrawiającej wody, w których leczono klimatem, hydropatią i innymi zabiegami dietetyczno-higienicznymi.

${ }^{9}$ „Gazeta Warszawska” 1857, nr 214, s. 2. Por. A.E. Odyniec, Listy z podróży, Warszawa 1875, s. 118. 
Warto więc postawić pytanie czy szeroko pojęta kultura uzdrowiskowa znalazła się również w kręgu zainteresowań twórców ówczesnej grafiki ilustracyjnej? Przecież artyści zaliczali się do grupy częstych gości różnych krajowych i zagranicznych kurortów. Warto prześledzić czy wśród różnych motywów ikonograficznych pojawiały się drzeworyty ukazujące obiekty i urządzenia znajdujące się w przestrzeni uzdrowisk? Jeżeli tak, to czy ilustrowano jedynie obiekty przeznaczone do celów balneoterapii i hydroterapii, czy też pojawiały się obiekty służące rozrywkom i umilaniu czasu wolnego? Ponadto czy na łamach XIX-wiecznej prasy ilustrowanej zamieszczano portrety osób zasłużonych dla rozwoju kultury uzdrowiskowej?

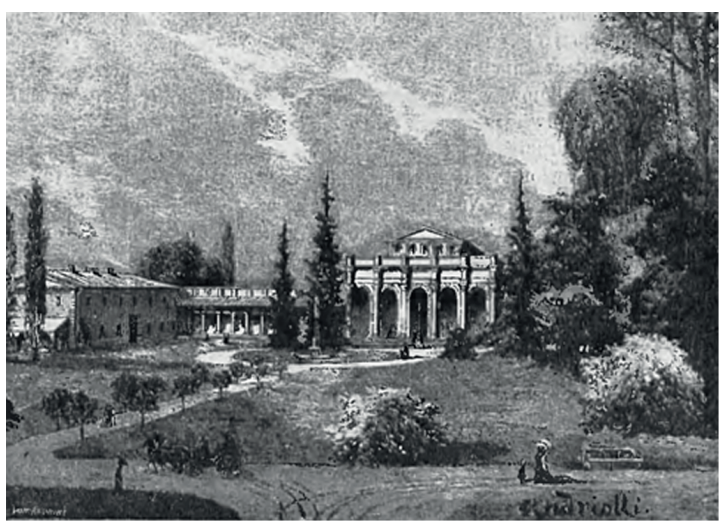

Ryc. 1. Zakład kapielowy w Busku, (drzeworyt wykonany przez Michała E. Andriollego), „Wędrowiec” 1891, nr 19

Podstawę do analizy stanowią czasopisma ilustrowane ukazujące się na terenie Królestwa Polskiego w drugiej połowie XIX i na początku XX w., przede wszystkim „Tygodnik Ilustrowany”, „Kłosy”, „Wędrowiec". Pisma te docierały głównie do tych kręgów społecznych, z których wywodzili się najczęściej kuracjusze uzdrowisk, a ponadto, jak wspomniałem wcześniej, periodyki te czytywane były na obszarze wszystkich ówczesnych ziem polskich.

Na pierwsze z postawionych pytań należy odpowiedzieć zdecydowanie twierdząco. Niemal każdy artykuł poświęcony prezentacji różnych krajowych i zagranicznych uzdrowisk zilustrowany bywał odpowiednio dobranymi i najczęściej pięknie wykonanymi drzeworytami. Ich autorami byli bardzo często wspomniani wcześniej najlepsi polscy ilustratorzy - rytownicy, malarze i graficy. Ilustracje umieszczane były nie tylko w numerach pism przy okazji artykułów poświęconych konkretnym uzdrowiskom, jako materiał ilustracyjny do nich, ale nieraz również samoistnie, stanowiąc pięknie prezentujące się ilustracje nawet na pierwszych stronach analizowanych czasopism. Na ilustracjach przedstawiano najczęściej najokazalsze budynki znajdujące się w poszczególnych uzdrowiskach, jak również ich wyposażenie (ryc. 1).

Prezentowano nie tylko obiekty służące terapii balneologicznej, jak: zakłady kąpielowe, kursale ${ }^{10}$, kurhausy ${ }^{11}$, łazienki mineralne i borowinowe, zakłady hydropatyczne, wanny kąpielowe i inne utensylia używane podczas kąpieli

\footnotetext{
${ }^{10}$ Kursal - budynek w kurorcie, w którym znajdowały się restauracje, kawiarnie, kasyna itp.

${ }^{11}$ Kurhaus - dom kuracyjny, hotel, pensjonat w kurorcie.
} 


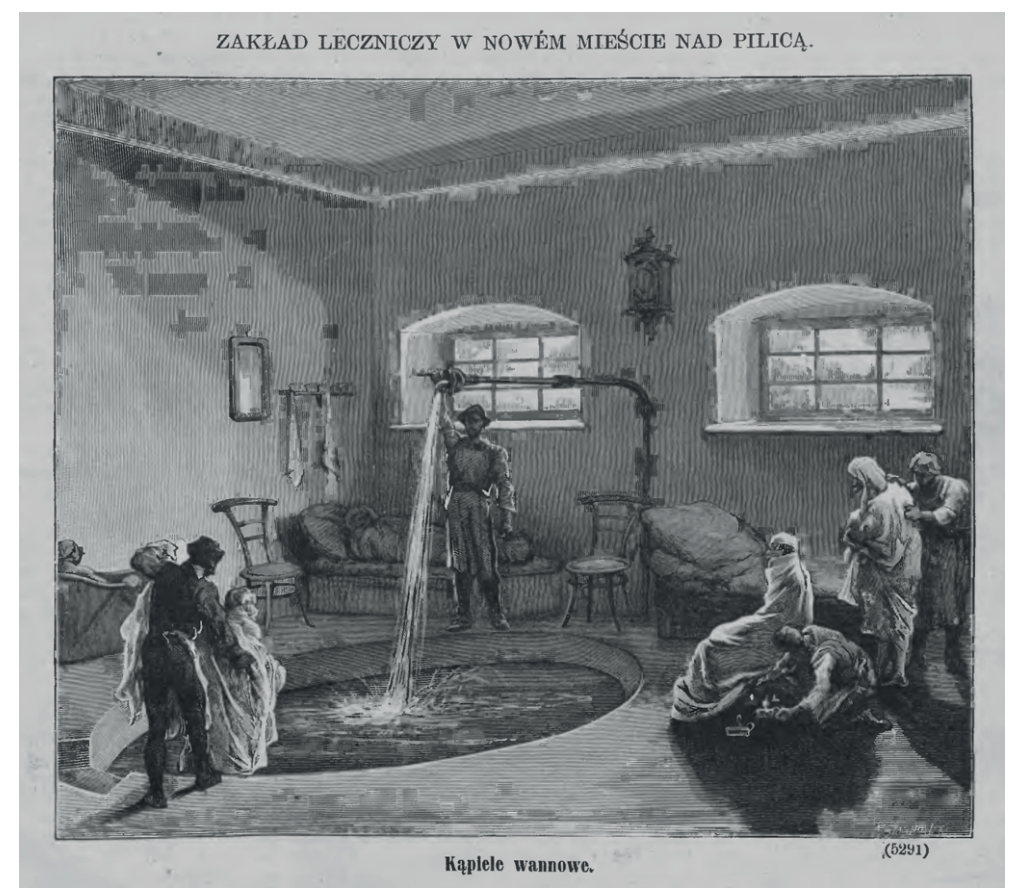

Ryc. 2. Kąpiele wannowe w Zakładzie Przyrodoleczniczym w Nowym Mieście nad Pilicą, „Kłosy” 1878, nr 724

leczniczych, ujęcia źródeł wody pitnej, tężnie, zakłady żętyczne itp., ale również inne obiekty znajdujące się w uzdrowisku lub w jego okolicach (ryc. 2). $\mathrm{Na}$ ilustracjach prezentowano więc budynki teatrów uzdrowiskowych, hotele i najbardziej eleganckie wille, parki zdrojowe, lokalne pomniki przyrody, altany i inne miejsca spotkan towarzyskich, perspektywy uzdrowisk i ich okolic, położone w okolicy zamki i ich ruiny, widoki pobliskich szczytów górskich, pomniki zasłużonych dla rozwoju balneologii i jeszcze cały szereg innych obiektów (np. sala gry w kasynie w Wiesbaden; mapa najważniejszych zdrojowisk w Galicji i Bukowinie; dom w Karlsbadzie, w którym mieszkał Adam Mickiewicz). Ilustracje ukazywały także modę uzdrowiskową, te ubiory, które służyły podczas kąpieli, ale także takie kreacje, które ubierano podczas picia wody, spacerów po parkach zdrojowych i w czasie spotkań towarzyskich.

Polskie czasopisma ilustrowane Królestwa Polskiego swoje szpalty przeznaczały przede wszystkim dla promowania „krajowych” uzdrowisk i zdrojowisk, czyli znajdujących się na terenie zaboru rosyjskiego oraz na obszarze Galicji i Bukowiny. W tym zakresie najczęściej zamieszczane były ilustracje ukazujące przestrzeń uzdrowiskową Ciechocinka, czyli najbardziej uznanego kurortu w Królestwie Polskim oraz Krynicy, a więc najbardziej wówczas prestiżowego 
uzdrowiska na ziemiach polskich. Ponadto pojawiły się ilustracje prezentujące obiekty w następujących uzdrowiskach, zdrojowiskach i stacjach klimatycznych: Jaszczurówka, Iwonicz, Lubień, Rabka, Swoszowice, Truskawiec, Żegiestów i Szczawnica położonych na terenie Galicji oraz Busko, Nałęczów, Sławinek, Solec, Nowe Miasto, Grodzisk, Ojców, Otwock, Brzegi, Jabłonna, Krasnobród, Złoty Potok, Inowłódz, Nowa Aleksandria (Puławy), Kazimierz Dolny, Mrozy, Suchedniów, Skierniewice, Birsztany oraz Druskienniki położone w granicach Królestwa Polskiego i na Kresach Wschodnich.

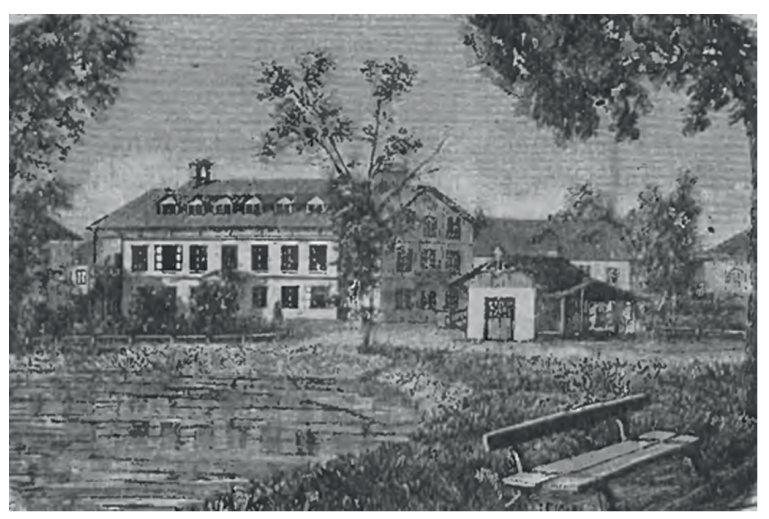

Ryc. 3. Zaktad hydropatyczny w Natęczowie, „Wędrowiec" 1891, nr 21

uzdrowisku, M.E. Andriolli zakończył swoje twórcze życie i został pochowany na miejscowym cmentarzu ${ }^{12}$.

Zdecydowanie mniej ilustracji $\mathrm{w}$ analizowanych czasopismach ilustrowanych Królestwa Polskiego ukazywało przestrzeń uzdrowiskową kurortów zagranicznych, takich jak Karlsbad, Wiesbadan, Marienbad, Gräfenberg, ale warto zasygnalizować, iż najrzadziej pojawiały się drzeworyty prezentujące zdrojowiska położone na terenie Śląska niemieckiego: Warmbrunn (Cieplice), Salzbrunn (Szczawno-Zdrój), Landeck (Lądek-Zdrój), Reinertz (Duszniki-Zdrój) i jeszcze inne mniej znane dolnośląskie ${ }^{13}$. Można przypuszczać, iż redakcje analizowanych czasopism ilustrowanych specjalnie unikały zamieszczania ilustracji z tych uzdrowisk, aby nie popierać miejscowości leczniczych, położonych w obrębie państwa „bojaźni Bożej a nienawiści bliźniego" ${ }^{14}$. Bojkot pruskich uzdrowisk miał

${ }^{12}$ Zob. szerzej: J. Wiercińska, Andriolli. Opowieść biograficzna, Warszawa 1981.

${ }^{13}$ Również nieliczne były reklamy tych kurortów zamieszczane na łamach prasy polskiej ukazującej się na terenie Królestwa Polskiego. Pisałem o tym w artykule: J. Kita, Promocja kultury uzdrowiskowej na łamach prasy w Królestwie Polskim po 1864 r., [w:] Historia polskiej kultury uzdrowiskowej, pod red. B. Płonki-Syroki i A. Syroki, Wrocław 2012, s. 151-172.

${ }^{14}$ Korespondencja, ,Wędrowiec” 1897, nr 35, s. 686. Podobnej treści konkluzje można znaleźć w wielu innych artykułach i korespondencjach zamieszczanych na łamach różnych pism Królestwa Polskiego. 
podtekst polityczny, wynikający z antypolskich działań podejmowanych przez kanclerza Otto von Bismarcka wobec Wielkopolski i Polaków po zjednoczeniu Niemiec w $1871 \mathrm{r}$.

Na łamach tygodników ilustrowanych Królestwa Polskiego pojawiały się także humorystyczne i satyryczne scenki rodzajowe dotyczące życia uzdrowiskowego. Warto natychmiast podkreślić, że ilustracje tego typu, jeżeli już pojawiała się konkretna miejscowość, dotyczyły raczej tzw. niepolskich uzdrowisk, jednak często i regularnie przez Polaków nawiedzanych, np. Marienbad, Karlsbad, Wiesbaden, Ostenda ${ }^{15}$ (ryc. 4).

W tego typu humorystycznych i satyrycznych obrazkach szczególnie prym wiódł Franciszek Kostrzewski, znakomity obserwator i szyderca ówczesnych stosunków społecznych panujących na ziemiach polskich (ryc. 5). Należy jednak podkreślić, iż zdecydowanie częściej kultura uzdrowiskowa, a szczególnie jej społecznotowarzyskie oblicze bywało przedmiotem niewinnych żartów, kpin, jak i nieco poważniejszej i uszczypliwej satyry ze strony dziennikarzy tzw. „wesołych gazetek"16, czyli

W Ostendzie.

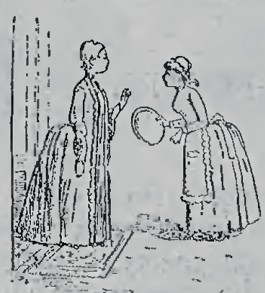

W domu.

- Pai Alfred sie pyta, czy może wejśćc?

- Ach, powied\%, żcm zupelnie nie ubrana...

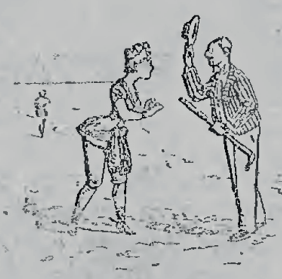

Nad morzem. pani...

- Przcpraszam, żem pana rano odprawila, ale bylam $w$ szlafroezkn, wicc nic mogłam pana przyjaci.
Ryc. 4. W Ostendzie, „Mucha. Pismo humorystyczne ilustrowane" 1889, nr 40, 22 IX/4 X 1889 r.

czasopism humorystyczno-satyrycznych ukazujących się w interesującym mnie okresie. Problem ten omówiłem w jednym z wcześniejszych swoich artykułów ${ }^{17}$.

Redakcje pism ilustrowanych Królestwa Polskiego zamieszczały również ilustracje prezentujące osoby najbardziej zasłużone dla rozwoju polskiej balneologii. Byli to najczęściej twórcy i propagatorzy rodzimego wodolecznictwa i lekarze zdrojowi mający na swoim koncie wiele znakomitych osiągnięć w tej dziedzinie. Na łamach czasopism ilustrowanych kilkakrotnie pojawiały się portrety najbardziej chyba zasłużonego dla rozwoju polskiej balneologii prof. Józefa Dietla (1804-1878). Do jego zasług należało rozpropagowanie fizykoterapii, leczenia

${ }^{15}$ Zob. np. „Kłosy” 1875, nr 528, s. 100, 104; 1875, nr 535, s. 216.

${ }^{16}$ Termin zapożyczony z tytułu książki M. Tobery, „Wesołe gazetki”. Prasa satyryczno-humorystyczna w Królestwie Polskim w latach 1905-1914, Warszawa-Lódź 1988.

${ }^{17}$ Zob. szerzej: J. Kita, Kultura uzdrowiskowa w polskiej satyrze w XIX i pierwszej połowie XX w., [w:] Kultura uzdrowiskowa w Europie, pod red. B. Płonki-Syroki, t. VI: Uzdrowiska $w$ procesie modernizacji (XIX-XXI wiek), pod red. B. Płonki-Syroki, L. Czyż, A. Syroki i K. Sudoł, Wrocław 2014, s. 351-372. 


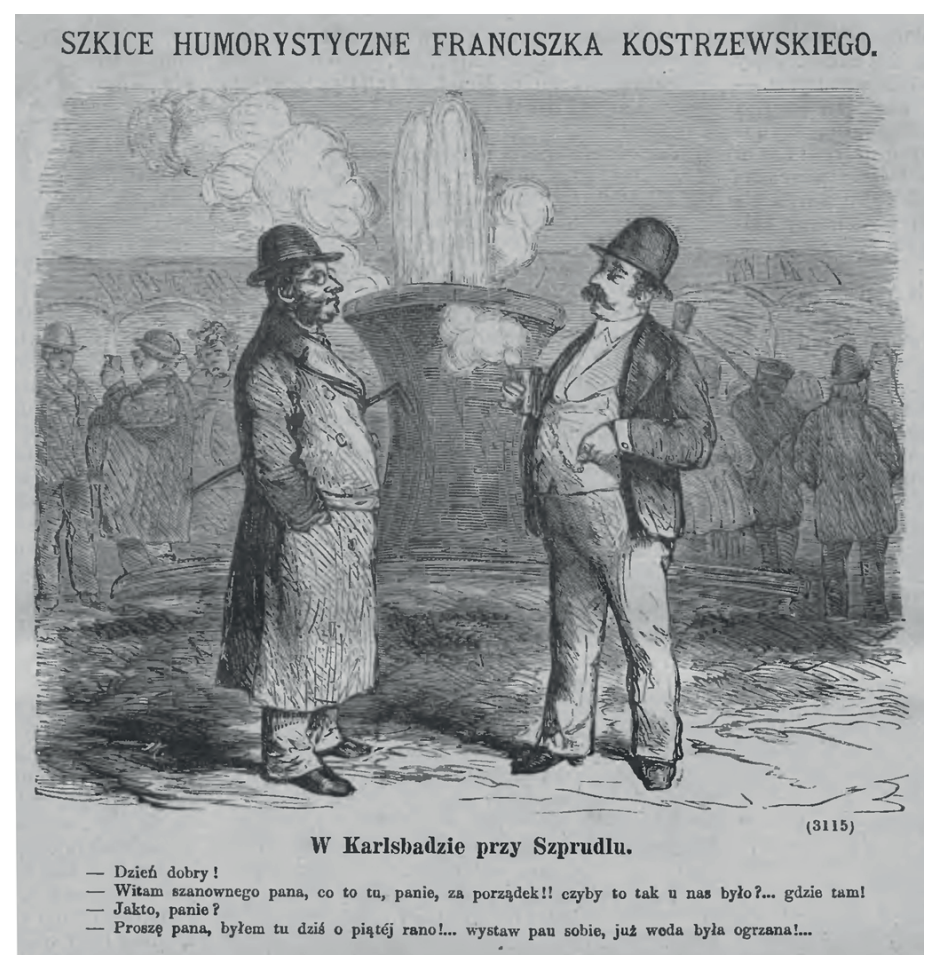

Ryc. 5. W Karlsbadzie przy Szprudlu, „Kłosy” 1875, t. XXI, nr 535

higieniczno-dietetycznego i balneologii. Jako pierwszy sklasyfikował polskie wody lecznicze, to dzięki niemu modne stały się krajowe, galicyjskie uzdrowiska z Krynicą na czele, a ponadto Rabka, Iwonicz, Szczawnica i Żegiestów. Zaraz po śmierci profesora Dietla w ówczesnej prasie ukazały się obszerne artykuły poświęcone jego osobie, opatrzone przy tym portretami „ojca polskiej balneologii”. Tytułem przykładu na pierwszej stronie nr 111 „Tygodnika Ilustrowanego" z 28 I (9 II) 1878 r. pojawił się drzeworyt autorstwa Aleksandra Regulskiego sporządzony na podstawie fotografii prof. J. Dietla wykonanej w znanym krakowskim zakładzie fotograficznym Walerego Rzewuskiego ${ }^{18}$ (ryc. 6).

Ponadto wszystkie czasopisma ilustrowane zamieściły fotografię innego lekarza, zasłużonego dla rozwoju polskiej balneologii, dr Michała Zieleniewskiego (1821-1896). Był on 30 lat lekarzem rządowym w Krynicy i położył ogromne zasługi dla rozwoju tego uzdrowiska. Dr M. Zieleniewski był autorem blisko stu publikacji poświęconych głównie balneologii i krynickim wodom leczniczym oraz pierwszym sekretarzem Komisji Balneologicznej w Krakowie.

${ }^{18}$ Dr Józef Dietl, „,Tygodnik Ilustrowany” 1878, nr 111, s. 81. 
Poszczególne periodyki publikowały również fotografie jeszcze innych lekarzy zasłużonych dla promocji i rozwoju lecznictwa uzdrowiskowego w poszczególnych częściach ziem polskich, m.in.: dra Alfonsa Pajewskiego, wieloletniego lekarza zdrojowego w Ciechocinku, współzałożyciela Stowarzyszenia Lekarzy Zdrojowych; dra Józefa Zawadzkiego (1865-1937), inicjatora Towarzystwa Doraźnej Pomocy Lekarskiej i pogotowia ratunkowego w Warszawie; dra Henryka Łuczkiewicza; dra Tytusa Chałubińskiego (1820-1889), jednego z prekursorów polskiego klimatolecznictwa i popularyzatora Zakopanego jako stacji klimatycznej wspomagającej leczenie chorób płucnych; dra Zygmunta Dobieszewskiego (1836-1896),

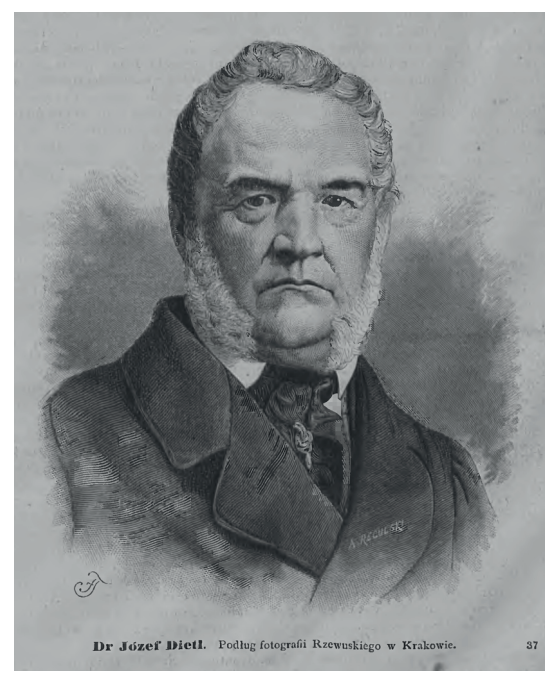

Ryc. 6. Dr Józef Dietl, „Tygodnik Ilustrowany" 1878, nr 111 który jako polski lekarz praktykował przez szereg lat w Marienbadzie, był współtwórcą „Tygodnika Lekarskiego” i redaktorem kilku innych pism medycznych; dra Juliana Zejdowskiego, współzałożyciela leczniczego zakładu kumysowego w Sławucie w 1877 r.; dra Jana Pileckiego (1821-1878), lekarza zdrojowego w Druskiennikach, przyjaciela Elizy Orzeszkowej, a także Franciszka Chłapowskiego i Konrada Dobrskiego, redaktora specjalistycznego dwutygodnika warszawskiego pt. „Zdrowie”.

W 1915 r. „Tygodnik Ilustrowany” w numerze 45, jeden z artykułów poświęcił wybitnym postaciom zasłużonym dla uzdrowiska w Nałęczowie, spoczywającym na miejscowym cmentarzu. Artykuł został zilustrowany m.in. zdjęciami nagrobków lekarzy i administratorów, którzy przyczynili się do rozwoju i funkcjonowania tego uzdrowiska: Fortunata Nowickiego, Konrada Chmielewskiego, Henryka Rodkiewicza i Juliana Morzyckiego ${ }^{19}$.

Powyższe rozważania mają na celu jedynie zasygnalizowanie problemu i wskazanie, iż ilustracje zamieszczane w czasopismach ilustrowanych mających debit na terenie Królestwa Polskiego w drugiej połowie XIX i w początkach XX w., mogą być z powodzeniem wykorzystywane w badaniach nad ówczesną kulturą uzdrowiskową. Najczęściej były to ilustracje opisowe, pełniące rolę uzupełniającą wobec tekstów poświęconych uzdrowiskom i różnym aspektom kultury uzdrowiskowej. Pojawiały się jednak również samodzielne ilustracje, będące same w sobie znakomitym źródłem do analizy. Drzeworyty poświęcone kulturze uzdrowiskowej wykonywali najlepsi wówczas polscy malarze i ilustratorzy z Juliuszem

${ }^{19}$ Z cmentarza w Bochotnicy, ,Tygodnik Ilustrowany” 1915, nr 45, s. 645-646. 


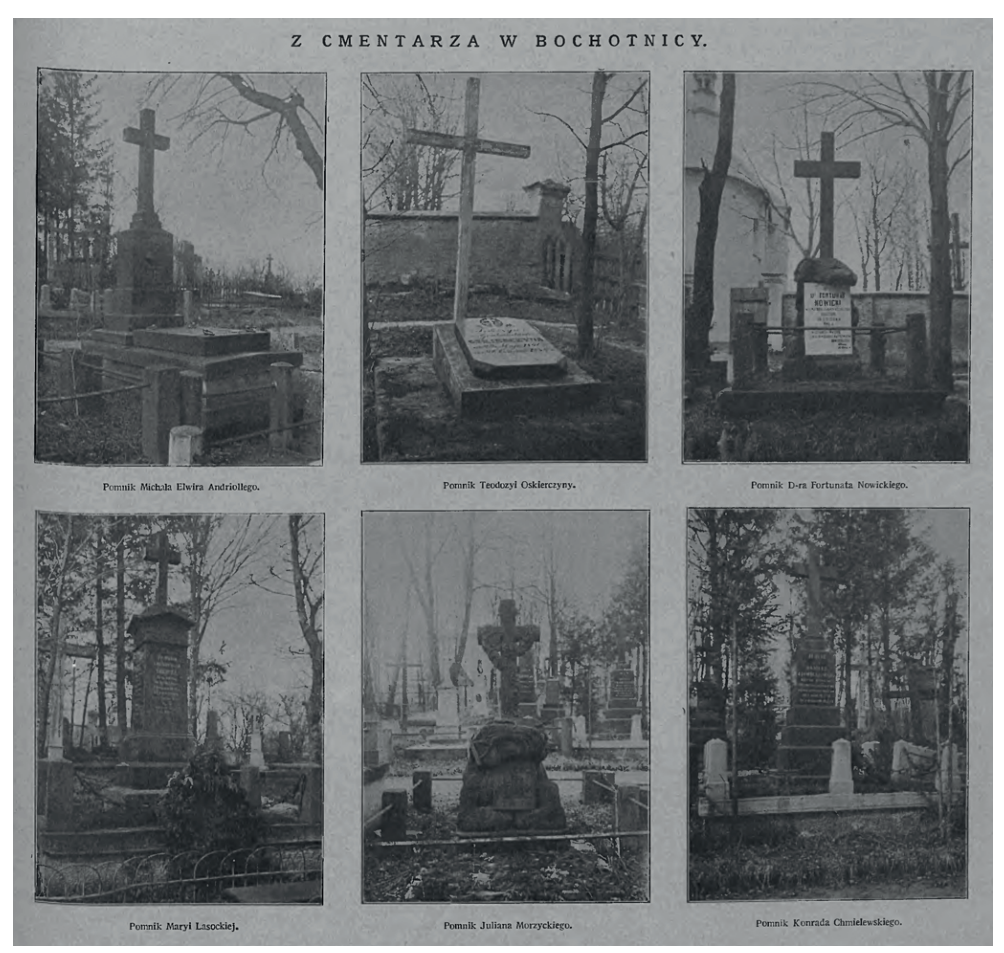

Ryc. 7. Z cmentarza w Bochotnicy (Nałęczów), „Tygodnik Ilustrowany” $1915, \mathrm{nr} 45$

Kossakiem, Elwiro Michałem Andriollim czy Franciszkiem Kostrzewskim na czele, co sprawia, że mają one również ogromną wartość estetyczną, będąc nieraz małymi dziełami sztuki. Podkolorowane drzeworyty, które w czarnobiałych barwach zdobiły czasopisma ilustrowane, nieraz pojawiały się później osobno jako poszukiwane dzieła sztuki. Poniżej chromolitografia przedstawiająca panoramę Zakładu Przyrodoleczniczego w Nowym Mieście nad Pilicą, autorstwa M.E. Andriollego, która wcześniej jako czarnobiały drzeworyt zamieszczona była $\mathrm{w}$ prasie. 


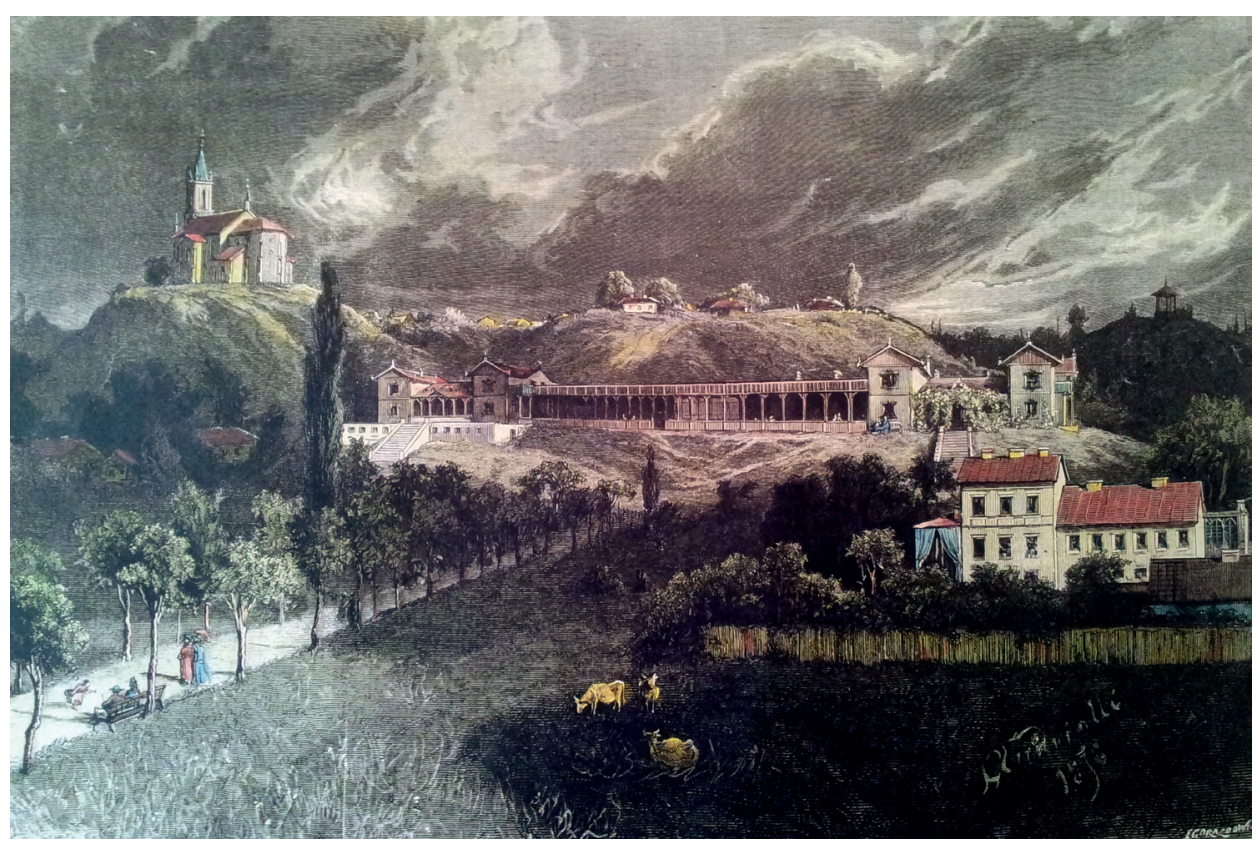

Ryc. 8. Panorama Zakładu Wodoleczniczego w Nowym Mieście nad Pilicą autorstwa M.E. Andriollego (chromolitografia ze zbiorów Muzeum Regionalnego w Nowym Mieście)

Jarosław Kita

\section{ILLUSTRATIONS FROM THE XIX ${ }^{\mathrm{TH}}$ CENTURY POLISH KINGDOM PRESS AS A SOURCE FOR A THE STUDY OF HEALTH RESORT CULTURE}

In the second half of the XIX ${ }^{\text {th }}$ century in Polish Kingdom there has been substantial progress in the development of printing techniques. This observations also applies to illustrative graphics. Woodcut as a technique of describing the event, designed to press pictures was cultivated by the most outstanding artists. Thanks it, illustrated magazines in Polish Kingdom developed quickly and belonged to the most widely read publications. In the papers of this magazines appeared number iconographic motif, such as: views of various buildings and equipment, panoramas and landscapes commanded places and cities, portrait of eminent and merit person.

At that time took place a revitalization of health resort culture in medical fields. As it were, the qualities of long known European resorts were being "discovered" anew and the native health resorts and spas were becoming more and more popular. Not only was the medical treatment the purpose to visit the spa but it become a fashion and important in term of social contacts. 
So let's pose the question if the wide concept of health resort culture also found in rang of interests of creators illustrative graphics then? Is among the various iconographic motifs appeared woodcut showing the facilities and equipment located in the areas of spas? If so, were only illustrated object designed for balneotherapy and hydrotherapy, or also appeared object designed for entertainment and making free time more pleasant. Moreover, were published portraits of merit for the development of the resort culture on the columns of the Polish Kingdom press?

The basis for this analysis were the illustrated magazines appearing on the terrain of Polish Kingdom in XIX $^{\text {th }}$ and early $X^{\text {th }}$ century. These periodicals were reaching mainly these social groups from which the patients of health resorts derived, and these magazines were widely read throughout all the land then Polish. 